The Journal of Laryngology \&amp; Otology

http://journals.cambridge.org/JLO

Additional services for The Journal of Laryngology \&amp; Otology:

Email alerts: $\underline{\text { Click here }}$

Subscriptions: $\underline{\text { Click here }}$

Commercial reprints: Click here

Terms of use : $\underline{\text { Click here }}$

\title{
Laser arytenoidectomy in children with bilateral vocal fold immobility
}

G Worley, Y Bajaj, L Cavalli and B Hartley

The Journal of Laryngology \& Otology / Volume 121 / Issue 01 / January 2007, pp 25 - 27

DOI: 10.1017/S0022215106001794, Published online: 09 June 2006

Link to this article: http://journals.cambridge.org/abstract_S0022215106001794

How to cite this article:

G Worley, Y Bajaj, L Cavalli and B Hartley (2007). Laser arytenoidectomy in children with bilateral vocal fold immobility. The Journal of Laryngology \& Otology, 121, pp 25-27 doi:10.1017/S0022215106001794

Request Permissions : $\underline{\text { Click here }}$ 


\title{
Laser arytenoidectomy in children with bilateral vocal fold immobility
}

\author{
G Worley, Y BajaJ, L Cavalli, B Hartley
}

\begin{abstract}
Bilateral vocal fold immobility in children is a challenging problem because a balance between good airway and voice quality has to be achieved. Surgery to improve the airway is often postponed or avoided because of fear of losing the voice. In this study our results of laser arytenoidectomy in children are described. This was a retrospective case notes review at a tertiary level paediatric ENT department. The six patients in this case series ranged from nine to 16 years old at the time of laser arytenoidectomy. Post-operative airway and voice quality were assessed. All children in the series had an adequate post-operative airway. Four of these patients had tracheostomies pre-operatively and achieved decannulation. All six patients rated their post-operative voice as better than pre-operatively. This is principally due to increased loudness associated with increased airflow through the larynx, particularly after tracheostomy decannulation. It is recommended that special care should be taken not to disturb the anterior two thirds of the vocal fold during the surgery in order to achieve a good post-operative voice outcome.
\end{abstract}

Key words: Arytenoidectomy; Larynx Surgical Procedures; Laser; Children; Voice

\section{Introduction}

Vocal fold paralysis in children is considered to be the second most common congenital anomaly of the paediatric airway. ${ }^{1}$ The authors prefer the use of the term 'vocal fold immobility' rather than 'paralysis', since the latter term suggests a purely neurological aetiology, which may be incorrect. Also, in many cases a degree of crico-arytenoid joint fixation has developed. The treatment of children with bilateral vocal fold immobility presents a challenge to the otolaryngologist, because a balance between a sufficiently patent airway and good voice quality has to be achieved. Bilateral vocal fold immobility is a potentially life threatening condition in children, which often requires surgical intervention.

Traditionally, there have been two main surgical approaches to bilateral vocal fold immobility: i) tracheostomy; ii) vocal fold lateralization. The surgical techniques described for fold immobility make use of both endoscopic and open approaches. The surgical management should aim to improve the patient's airway and at the same time avoid a breathy or weak voice. In this study our results of laser arytenoidectomy in six consecutive children are described.

\section{Patients and methods}

Between May 2000 and November 2004, six arytenoidectomies were performed in children under the care of the senior author $(\mathrm{BH})$. All patients had bilateral vocal fold immobility. Four of these patients had a tracheostomy in situ at the time of the procedure. The surgery was performed by suspension micro-laryngoscopy under general anaesthesia. Anaesthesia for the procedure was administered and by spontaneous ventilation taking all precautions for laser. An appropriately sized laryngoscope was inserted into the vallecula and suspended to expose the larynx. A Zeiss microscope, using a $400 \mathrm{~mm}$ lens coupled with a $\mathrm{CO}_{2}$ laser was used in all cases. Settings used for the $\mathrm{CO}_{2}$ laser were 10 watts in continuous mode. The vocal process of one arytenoid and a small part of the anterior body of the arytenoid were removed using the laser (Figure 1). Care was taken to avoid injury to the inter-arytenoid mucosa. Care was also taken to leave the anterior two thirds of the vocal fold undisturbed (Figure 2). Patients without tracheostomy were given intra-operative dexamethasone to reduce airway oedema. All patients received a seven days course of antibiotics.

Post-operative airway and voice outcomes were assessed subjectively from the patient's own experience. The airway was also assessed objectively by pre-operative and post-operative photographs. The post-operative voice was subjectively rated by the patient as 'better', 'same' or 'worse' than before surgery. 


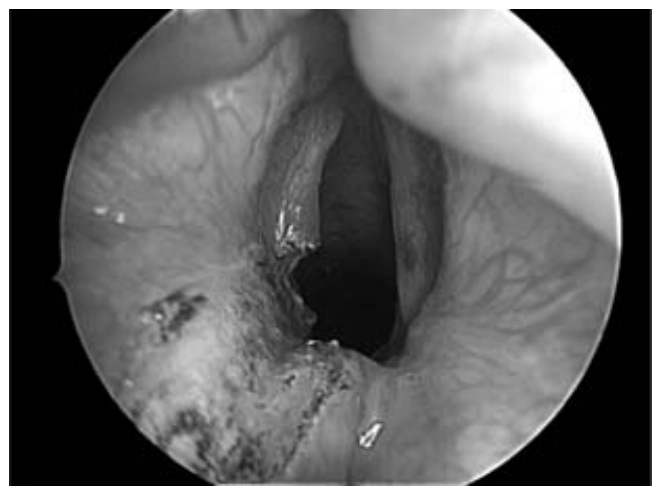

FIG. 1

Close up endoscopic view of laser arytenoidectomy.

\section{Results}

The patients in this case series ranged from nine to 16 years at the time of laser arytenoidectomy. The average age at the time of operation was 14 years. All children were subject to a detailed history and examination, in order to establish the diagnosis of bilateral vocal fold immobility. If flexible laryngoscopy was not possible in the out-patient clinic, then micro-laryngoscopy with dynamic examination of the larynx was performed under general anaesthetic.

Four of the patients had bilateral crico-arytenoid fixation secondary to prolonged intubation. One patient had bilateral crico-arytenoid fixation secondary to neonatal perichondritis of the larynx. One patient had bilateral fold immobility of unknown aetiology.

In this group of six patients, a total of six arytenoidectomies were performed. One patient had three minor supraglottic laser procedures (by another surgeon) before undergoing definitive arytenoidectomy. The average follow up for these patients was 18 months. Four of the six patients had a tracheostomy in situ before arytenoidectomy was performed.

The airway was subjectively rated as 'better' than before surgery in all six patients. All four tracheostomy patients were successfully decannulated within three months of the arytenoidectomy procedure. In all patients there was a subjective improvement in

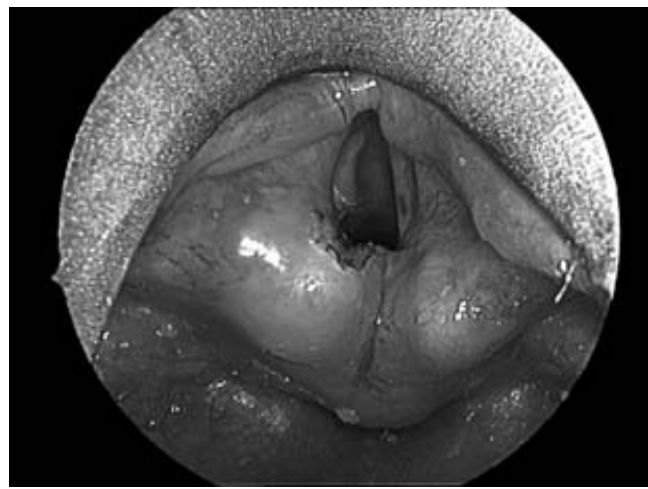

FIG. 2

Overview of the larynx at the end of laser arytenoidectomy. the voice after the procedure. All patients rated their post-operative voice as 'better', and none rated the voice as 'same' or 'worse'. None of the patients in this series needed a revision operation and there were no complications during or after the procedures.

\section{Discussion}

Although unilateral vocal fold immobility is a relatively common congenital abnormality, bilateral vocal fold immobility is less commonly encountered, and represents a difficult management issue for the otolaryngologist. Provision of an adequate airway is of paramount importance and this may present as an emergency, usually requiring tracheostomy. A secondary, but still very important issue is the vocal quality which may be normal but weakened by tracheostomy or airway limitation, with the potential for further deterioration if surgical treatment is not optimal.

It should be remembered that between 15 per cent and 70 per cent of children will regain some degree of vocal fold function in the due course of time ${ }^{1-4}$ and thus a child should be given adequate time, to observe for spontaneous recovery, before considering any surgical procedure. An interval of six to 12 months between diagnosis and treatment is considered appropriate. ${ }^{5}$ It has been recommended that particularly in children with idiopathic vocal fold immobility, arytenoidectomy should be postponed until adolescence. ${ }^{4}$ Keeping this in mind, most of the arytenoidectomies in this series were performed on children in their teens.

Causes of bilateral vocal fold immobility include birth trauma, iatrogenic causes, neurological causes, idiopathic and other miscellaneous causes. ${ }^{4}$

Many treatment options are available for the airway compromised by bilateral vocal fold immobility. The traditional gold standard has been tracheostomy, ${ }^{6}$ but many other techniques have been described including arytenoidectomy, vocal fold lateralization, partial cordotomy and cordectomy. The main treatment objective is to achieve a good airway with preservation or improvement of the voice.

Both extra-laryngeal and endoscopic approaches have been used for the treatment of bilateral vocal fold immobility. The extra-laryngeal approach was introduced by Jackson in 1922, who advocated ventriculo-cordectomy. ${ }^{7}$ This was followed by introduction of submucosal fold resection by Hoover in $1932,{ }^{8}$ and lateral fixation of the vocal fold by King in 1939. ${ }^{9}$ Woodman, in 1946, proposed arytenoidectomy using an extra-laryngeal posterolateral approach in addition to suturing the vocal process to the inferior cornu of thyroid cartilage to lateralize the vocal fold. ${ }^{10}$

Subsequently, endoscopic approaches were introduced. These included Thornell's arytenoidectomy by electrocautery, ${ }^{11}$ Ossoff's laser arytenoidectomy, ${ }^{12,13}$ and posterior cordotomy by Dennis and Kashima. ${ }^{14,15}$ 
The use of a microscope mounted $\mathrm{CO}_{2}$ laser and suspension laryngoscopy enables the surgeon to perform precise surgery to the larynx. Other features of the $\mathrm{CO}_{2}$ laser include good haemostasis and decreased intra- and post-operative oedema.

Some technical difficulties can be encountered during the procedure. Complete visualization of the arytenoid cartilage is sometimes challenging and bleeding from the inferior laryngeal artery may sometimes be troublesome. ${ }^{16}$ The laser may also cause thermal damage to surrounding structures, and particular care should be taken to avoid the inter-arytenoid mucosa, for fear of escar formation. $^{12,17,18}$

We feel that this technique is both simple to perform and effective, in terms of voice and airway outcomes. Removal of the vocal process allows an adequate posterior glottic chink for breathing, whilst preserving the mucosal wave in the membranous part of the vocal fold.

- Bilateral vocal fold immobility in children is a challenging problem owing to the difficult balance between voice and airway

- This paper presents the results of laser arytenoidectomy in a paediatric population

- All six children in this series had adequate post-operative airway and voice

- The importance of not disturbing the anterior two thirds of the vocal fold during surgery is emphasized

There is a considerable reluctance, among patients and their carers, to undergo arytenoidectomy, for fear of worsening the voice. Traditional teaching tells us that an increase in the airway must be "paid for' by deterioration in the voice; however this is not borne out by our results. Other authors have made similar observations and have noted that preservation of the anterior vocal fold allows airway enlargement with good voice preservation. $5,14,19$ The authors suspect that worsened voice outcomes are rarer than commonly perceived, particularly if the procedure is performed in the manner described. It is possible that a reduction in the quality of the mucosal wave, caused by the arytenoidectomy, is balanced by an increase in the strength of the voice due to the widened airway, thus improving overall intelligibility.

\section{Conclusions}

This series illustrates that laser arytenoidectomy in children with bilateral vocal fold immobility, can produce good outcomes for both airway and voice. It is recommended that special care should be taken not to traumatize the anterior two thirds of the vocal fold.

\section{References}

1 Holinger LD, Holinger PC, Holinger PH. Etiology of bilateral abductor vocal cord paralysis: a review of 389 cases. Ann Otol Rhinol Laryngol 1976;85:428-36

2 Cohen SR, Geller KA, Birns JW, Thompson JW. Laryngeal paralysis in children. Ann Otol Rhinol Laryngol 1982;91:417-21

3 de Gaudemar I, Roudaire M, Francois M, Nancy P. Outcomes of laryngeal paralysis in neonates: a long term retrospective study of 113 cases. Int J Pediatr Otorhinolaryngol 1996;34:101-10

4 Daya H, Hosni A, Bejar-Solar I, Evans JNG, Bailey CM. Paediatric vocal fold paralysis-a long term retrospective study. Arch Otorhinolaryngol 2000;126:21-5

5 Friedman EM, deJong AL, Sulek M. Pediatric bilateral vocal fold immobility: the role of carbon dioxide laser posterior transverse partial cordectomy. Ann Otol Rhinol Laryngol 2001;110:723-8

6 Gray SD, Kelly SM, Dove H. Arytenoid separation for impaired paediatric vocal fold mobility. Ann Otol Rhinol Laryngol 1994;103:510-15

7 Jackson C. Ventriculocordectomy, a new operation for the cure of goitrous glottic stenosis. Arch Surg 1922;4:257-74

8 Hoover WB. Bilateral abductor paralysis, operative treatment of submucous of the vocal cord. Arch Surg 1932;15: 337-55

9 King BT. A new and function restoring operation for bilateral abductor cord paralysis. JAMA 1939;112:814-23

10 Woodman D. A modification of the extralaryngeal approach to arytenoidectomy for bilateral abductor paralysis. Arch Otolaryngol 1946;43:63-5

11 Thornell WC. Intralaryngeal approach for arytenoidectomy in bilateral abductor vocal cord paralysis. Arch Otolaryngol 1948;47:505-8

12 Ossof RH, Sisson GA, Duncavage JA. Endoscopic laser arytenoidectomy for the treatment of bilateral vocal cord paralysis. Laryngoscope 1984;94:1293-7

13 Ossof RH, Duncavage JA, Shapshay SM. Endoscopic laser arytenoidectomy revisited. Ann Otol Rhinol Laryngol 1990;99:764-71

14 Dennis DP, Kashima H. Carbon dioxide laser posterior cordectomy for treatment of bilateral vocal cord paralysis. Ann Otol Rhinol Laryngol 1989;98:930-4

15 Kashima HK. Bilateral vocal fold motion impairment: pathophysiology and management by transverse cordotomy. Ann Otol Rhinol Laryngol 1991;100:717-21

16 Bizakis JG, Papadakis CE, Karatzanis AD, Skoulakis CE, Kyrmizakis DE, Hajiioannou JK et al. The combined endoscopic CO2 laser posterior cordotomy and total arytenoidectomy for treatment of bilateral vocal cord paralysis. Clin Otolaryngol 2004;29:51-4

17 Lim RY. Laser arytenoidectomy. Arch Otorhinolaryngol 1985;111:262-3

18 Crumley RL. Endoscopic laser medial arytenoidectomy for airway management in bilateral laryngeal paralysis. Ann Otol Rhinol Laryngol 1993;102:81-4

19 Segas J, Stavroulakis P, Manolopoulos L, Yiotakis J, Adamopoulos G. Management of bilateral vocal fold paralysis: Experience at Univeristy of Athens. Otolaryngol Head Neck Surg 2001;124:68-71

Address for correspondence:

Mr Yogesh Bajaj,

2, Tall Trees,

Leeds

LS17 7WA.

Fax: $0044(0) 1132663305$

Email: ybajaj@hotmail.co.uk

Mr Y Bajaj takes responsibility for the integrity of the content of the paper.

Competing interests: None declared 